\title{
Recurrent Goiters
}

\author{
Ranil Fernando
}

\section{Abstract}

A recurrent goiter is the regrowth of thyroid tissue after thyroidectomy. The causes of recurrence following surgery for the benign disease can be broadly attributed to inadequate surgery, embryological remnants left behind inadvertently, and the development of a malignancy in the remnant.

Recurrence after surgery for the benign disease should be preventable. Subtotal thyroidectomy (STT) was the main operation for goiters until the 1980s. The main issue with a subtotal surgery is a recurrence. One of the primary reasons why STT fails can be attributed to the fact that STT does not treat the underlying generalized disease adequately. The consensus is emerging that the best surgical option for multinodular goiter is total thyroidectomy. Even after "total" thyroidectomy, there is recurrence, what is left behind is related to the three embryological remnants of thyroid, namely pyramidal lobe recurrences, recurrence of the tubercle of Zuckerkandl, and thyrothymic recurrences. The surgical technique at the initial total thyroidectomy must be meticulous, ensuring that all embryological remnants are excised properly.

Goiter recurrence is a failure of surgical treatment of goiter. Inadequate surgery and failure to excise all thyroid tissues are two preventable causes for recurrence. The technique of reoperative thyroidectomy must include capsular dissection, removal of all embryological remnants, and parathyroid autotransplantation.

Surgery for recurrent goiter is challenging. It is thought to entail a higher complication rate and complication rates may be high in inexperienced hands; low complication rates have been achieved in specialized centers. The fear of complications should not deter experienced surgeons from performing reoperative thyroid surgery. In terms of technique, the lateral approach to thyroid offers a good alternative for recurrent goiters. A meticulous technique and parathyroid autotransplantation will help minimize the complication rate.

Keywords: Recurrent goiter, Thyroid surgery, Total thyroidectomy.

World Journal of Endocrine Surgery (2019): 10.5005/jp-journals-10002-1247

\section{INTRODUCTION}

A recurrent goiter is the regrowth of thyroid tissues after thyroidectomy. This may occur after surgery for benign disease or malignancy of thyroid. While recurrence after surgery for benign disease should be preventable, recurrence after malignant disease depends on many factors.

Recurrences of multinodular goiter (MNG) account for up to $12 \%$ of all thyroid operations. ' Surgery for recurrent goiter is associated with a higher complication rate.

The causes of recurrence can be broadly attributed to:

- Inadequate surgery

- Embryological remnants left behind inadvertently

- Development of a malignancy in the remnant

- Recurrence of a cancer in the thyroid.

It is important to discuss and analyze the reasons for recurrence in order to prevent recurrences.

\section{Inadequate Surgery}

From early times, thyroid surgery was embroiled in controversy. First, thyroidectomy was supposed to have been done by Albucasis (El Zahrawi) in 975 AD. ${ }^{2,3}$

The first credible reports of thyroid surgery came from the School of Salerno in the 13th century, and by 1850 only 14 successful partial or total thyroidectomies had been reported across Europeresults were appalling. ${ }^{2,3}$ In 1850, the French Academy of Medicine banned thyroidectomy due to the fear of complications and uncertainty in histological classification. Subtotal thyroidectomy (STT) was the main operation for goiters until the 1980s. The main issue with a subtotal surgery is recurrence. ${ }^{4-8}$
Department of Surgery, Faculty of Medicine, University of Kelaniya-Sri Lanka, Ragama, Western Province, Sri Lanka

Corresponding Author: Ranil Fernando, Department of Surgery, Faculty of Medicine, University of Kelaniya-Sri Lanka, Ragama, Western Province, Sri Lanka, e-mail: ranilfern@sItnet.lk

How to cite this article: Fernando R. Recurrent Goiters. World J Endoc Surg 2019;11(1):15-18.

Source of support: Nil

Conflict of interest: None

One of the primary reasons why subtotal thyroidectomy fails can be attributed to the fact that STT does not treat the underlying generalized disease process adequately. Multinodular goiter and toxicity are the main indications for thyroidectomy in benign disease. Subtotal thyroidectomy does not offer a curative operation in either of these conditions. Hence, recurrence is to be expected after STT. The practice of offering STT continued for over 100 years due to the fear of complications alluded to the above.

Multinodular goiter is thought to be the result of primarily two factors. The first factor is genetic heterogeneity of follicular cells with regard to function (i.e., thyroid hormone synthesis) and growth. Genetic analysis has identified two chromosomal regions (MNG-1 and Xp 22) in multinodular goiter. ${ }^{9}$

The second factor is the acquisition of new qualities that were not present in mother cells and become inheritable during further replication. The pathological process of MNG disease affects the whole gland. If part of a MNG is removed, the remnant is likely to grow again (Figs 1 and 2).

(c) The Author(s). 2019 Open Access This article is distributed under the terms of the Creative Commons Attribution 4.0 International License (https://creativecommons. org/licenses/by-nc/4.0/), which permits unrestricted use, distribution, and non-commercial reproduction in any medium, provided you give appropriate credit to the original author(s) and the source, provide a link to the Creative Commons license, and indicate if changes were made. The Creative Commons Public Domain Dedication waiver (http://creativecommons.org/publicdomain/zero/1.0/) applies to the data made available in this article, unless otherwise stated. 


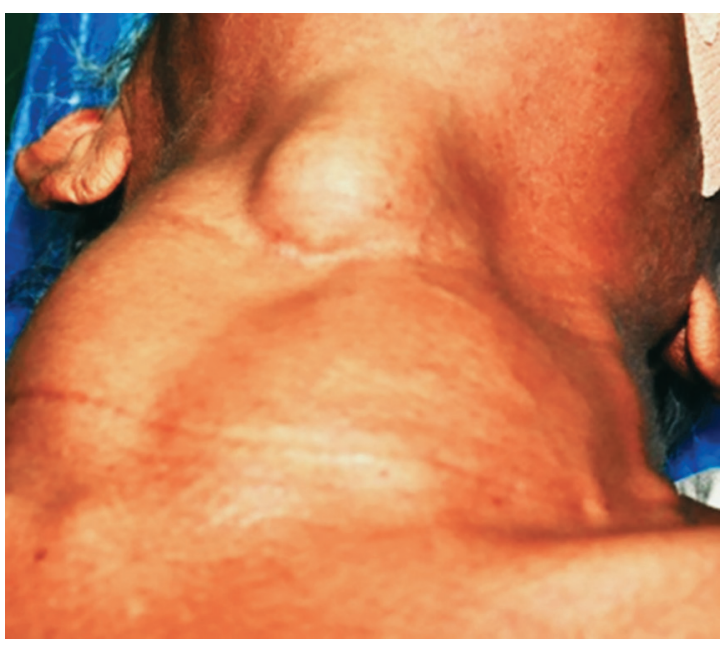

Fig. 1: Recurrence

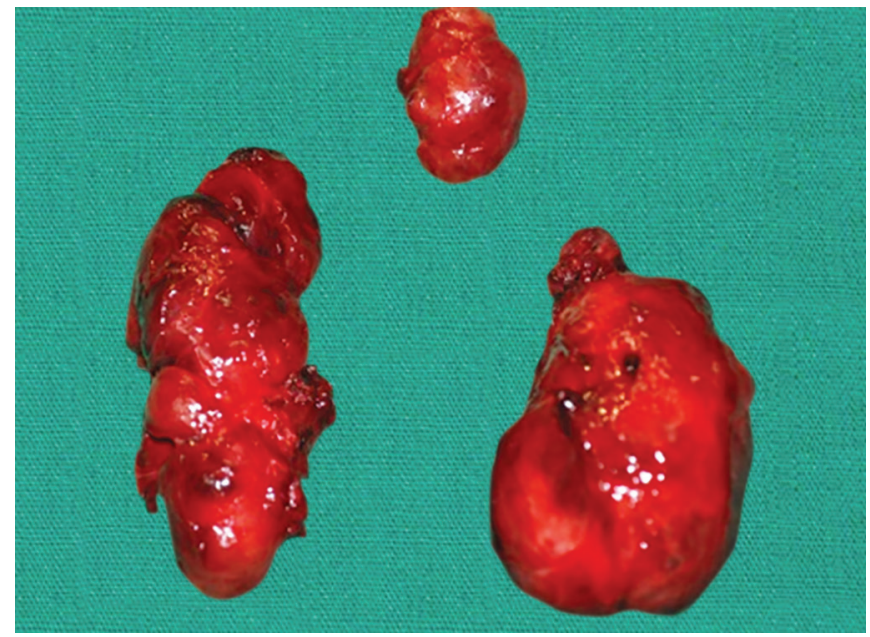

Fig. 2: Operative specimen

Administration of thyroxine has been tried to minimize the risk of recurrence following STT. There is a flaw in the theoretical basis for the administration of thyroxine. It assumes that the regrowth of thyroid tissues depends primarily on the action of thyroid stimulating hormone (TSH) on the thyrocytes. While TSH is an important stimulator of thyrocyte growth, there are several other factors that will cause regrowth of thyroid tissues. ${ }^{10,11}$

Studies from non-endemic countries like Scandinavia reported no preventive effect on recurrence by thyroxine. ${ }^{5}$ On the contrary, studies from endemic regions have shown that thyroxine administration has been useful. ${ }^{12}$ This dichotomy highlights the multifactorial nature of the origin of MNG-TSH is NOT the only stimulus for pathological growth of thyrocytes; hence, TSH suppression in not a reliable way of preventing recurrence.

The consensus is emerging that the best surgical option for multinodular goiter is total thyroidectomy. ${ }^{13-18}$ Unfortunately, recent reviews have shown that there is a recurrence rate even after total thyroidectomy. ${ }^{19,20}$

This raises a pertinent question-How could recurrence occur after total thyroidectomy? The answer is simple. Though the surgeon believed that it was a total excision, there were remnants of thyroid tissues left behind. How is this possible?

\section{Surgery for Recurrent Goiter}

Studies ${ }^{19,21}$ have shown that what is left behind is related to the three embryological remnants of thyroid, namely, pyramidal lobe recurrences (Figs 3 and 4), recurrence of the tubercle of Zuckerkandl, and thyrothymic recurrences. These may occur as isolated recurrences or combined recurrences (Fig. 3).

In up to $50 \%$ people, the inferior end of the thyroglossal duct (failure to obliterate) persists. The tubercle of Zuckerkandl is found in about $80-95 \%$ of patients and the incidence varies between right and left sides. ${ }^{22,23}$ Rests of the thyroid tissues within the thyrothymic area are relatively common (50\%), often mistaken for lymph nodes or parathyroids. About $80 \%$ of identified rests are attached to the thyroid properly by a pedicle of thyroid tissues. ${ }^{24}$

The surgical technique at the initial total thyroidectomy must be meticulous, ensuring that all embryological remnants are excised properly. Dissection must be done beyond the thyroid notch superiorly, down to the sternal notch inferiorly, and the carotid sheath laterally.

The lateral approach to thyroid is a good technique in our experience. It is a good alternative to the standard anterior approach. ${ }^{25}$ The key is the development of the plane between

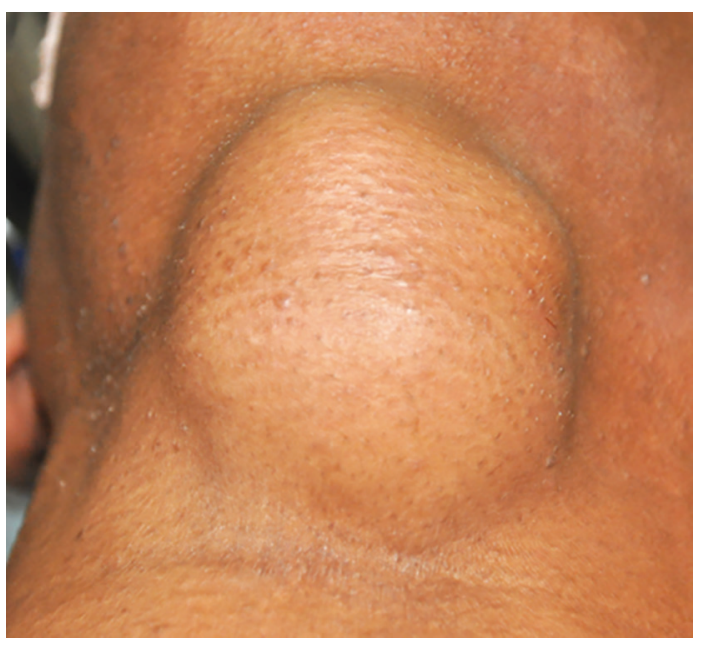

Fig. 3: Pyramidal lobe recurrence

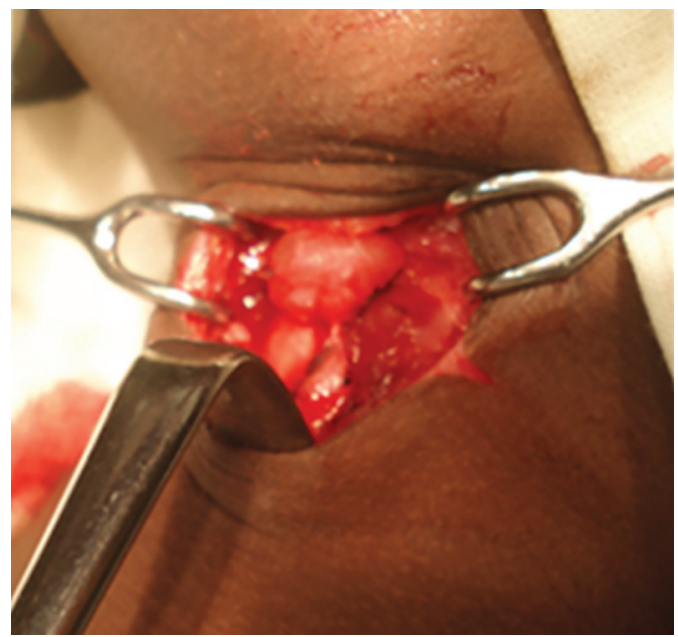

Fig. 4: Operative specimen 


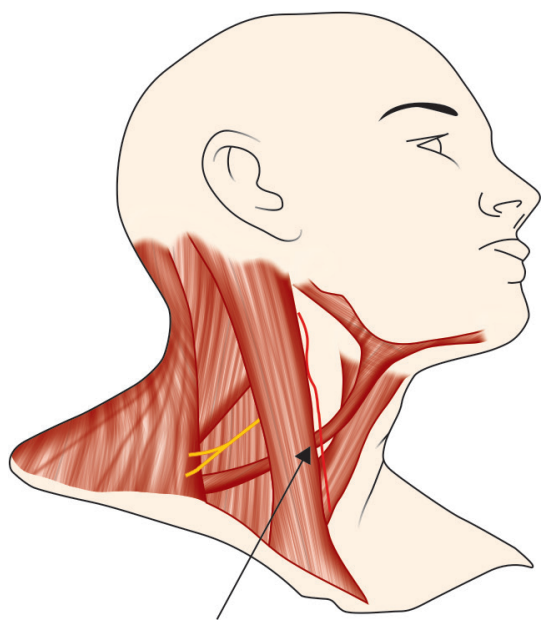

Fig. 5: Plane of dissection

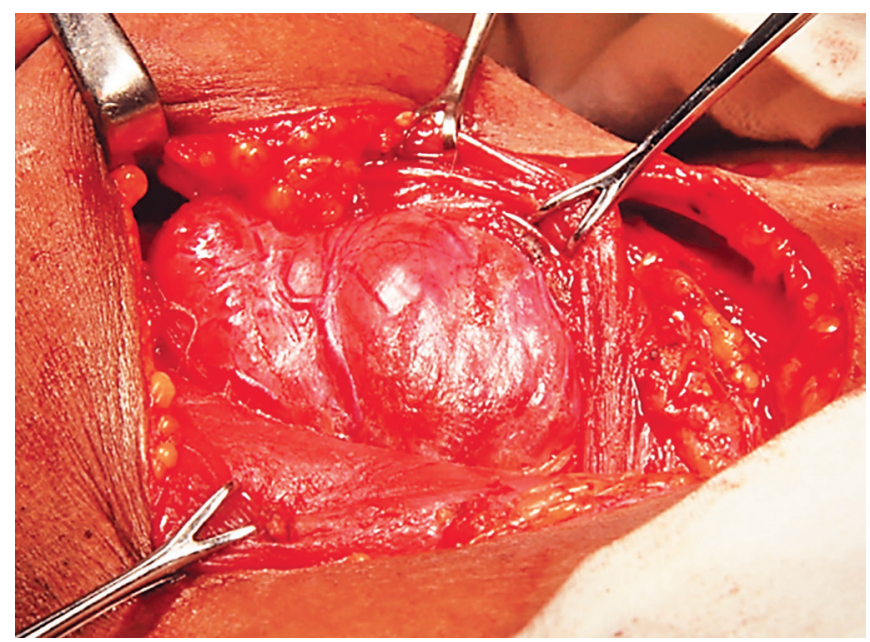

Fig. 6: View during surgery

ipsilateral sternomastoid and strap muscles (Figs 5 and 6) as it is a "virgin" plane. Active parathyroid autotransplantation tends to minimalize hypocalcemia.

\section{Complications}

Reoperative surgery can be performed with minimum morbidity in high volume centers. ${ }^{26,27}$

The complication rate of $1-2 \%$ which is considered to be acceptable for primary surgery can be achieved in reoperative surgery in experienced hands. While less extensive surgery may be associated with a lower complication rate, the risk of recurrence is much higher with a lesser procedure. Fear of complications is not a reason to deny reoperative surgery, but the surgery should be done by experienced surgeons who work in high volume centers. ${ }^{26,27}$ The role of intraoperative neuromonitoring (IONM) in reoperative thyroid surgery is debatable due to increased cost, poor positive predictive value, and lack of reliability in detecting nonfunctioning nerves intraoperatively. ${ }^{28}$ INOM needs further evaluation in reoperative thyroid surgery.

\section{Conclusion}

Goiter recurrence is a failure of surgical treatment of goiter. Inadequate surgery and failure to excise all thyroid tissues are two preventable causes for recurrence. The technique of reoperative thyroidectomy must include capsular dissection, removal of all embryological remnants, and parathyroid autotransplantation.

Surgery for recurrent goiter is challenging. It is thought to entail a higher complication rate and complication rates may be high in inexperienced hands; low complication rates have been achieved in specialized centers. The fear of complications should not deter experienced surgeons from performing reoperative thyroid surgery. In terms of technique, the lateral approach to thyroid offers a good alternative for recurrent goiters. A meticulous technique and parathyroid autotransplantation will help minimize the complication rate.

\section{References}

1. Moalem J, Suh I, et al. Treatment and prevention of recurrence of multinodular goiter: an evidence-based review of the literature. World J Surg July 2008:32(7):1301-1312. DOI: 10.1007/s00268-0089477-0.

2. Ignjatovic M. Overview of the history of thyroid surgery. Acta Chir lugosl 2003;50:9-36.

3. Sarkar S, Banerjee S, et al. A review on the history of 'thyroid surgery'. Indian J Surg 2016 Feb;78(1):32-36. DOI: 10.1007/s12262-015-1317-5.

4. Yoldas T, Makay O, et al. Should subtotal thyroidectomy be abandoned in multinodular goiter patients from endemic regions requiring surgery? Int Surg 2015 Jan;100(1):9-14. DOI: 10.9738/ INTSURG-D-13-00275.1.

5. Röjdmark J, Järhult J. High long term recurrence rate after subtotal thyroidectomy for nodular goitre. Eur J Surg 1995 Oct;161(10): 725-727.

6. Pappalardo G, Guadalaxara A, et al. Total compared with subtotal thyroidectomy in benign nodular disease: personal series and review of published reports. Eur J Surg 1998 Jul;164(7):501-506. DOI: 10.1080/110241598750005840.

7. Cappellani A, Di Vita M, et al. Ann Ital Chir 2008;79:247-254.

8. Cirocchi R, Trastulli S, et al. Cochrane Database Syst Rev 2015 Aug 7: CD010370. DOI: 10.1002/14651858.CD010370.pub2.

9. Medeiros-Neto G, Multinodular goiter in thyroid disease manager is produced and edited Leslie J De Groot. Last updated: September 26, 2016.

10. Derwahl M, Studer H. Multinodular goitre: 'much more to it than simply iodine deficiency'. Baillieres Best Pract Res Clin Endocrinol Metab 2000 Dec;14(4):577-600. DOI: 10.1053/beem.2000.0104.

11. Peter $\mathrm{HJ}$, Gerber $\mathrm{H}$, et al. Pathogenesis of heterogeneity in human multinodular goiter. A study on growth and function of thyroid tissue transplanted onto nude mice. J Clin Invest 1985 Nov;76(5):1992-2002. DOI: 10.1172/JCI112199.

12. Kulacoglu $H$, Dener $C$, et al. Thyroxine prophylaxis after bilateral subtotal thyroidectomy for multinodular goiter. Endocr J 2000; 47(3):349-352.

13. Perzik SL. The place of total thyroidectomy in the management of 909 patients with thyroid disease. Am J Surg 1976 Oct;132(4):480-483.

14. Reeve TS, Delbridge L, et al. Total thyroidectomy. The preferred option for multinodular goiter. Ann Surg 1987 Dec;206(6):782-786.

15. Peix JL, Van Box Som P. Role of total thyroidectomy in the treatment of benign thyroid diseases. Ann Endocrinol 1996;57(6):502-507.

16. Liu $Q$, Djuricin G, et al. Total thyroidectomy for benign thyroid disease. Surgery 1998 Jan;123(1):2-7.

17. Malcolm $\mathrm{H}$. Wheeler total thyroidectomy for benign thyroid disease. Lancet, 23 May 1998;351:1526-1527. DOI: 10.1016/S01406736(05)61116-6.

18. Tezelman S, Borucu I, et al. The change in surgical practice from subtotal to near-total or total thyroidectomy in the treatment of patients with benign multinodular goiter. World J Surg 2009;33(3):400-405. DOI: 10.1007/s00268-008-9808-1. 
19. Snook KL, Stalberg PLH, et al. Recurrence after total thyroidectomy for benign multinodular goiter. World J Surg March 2007;31(3):593-598. DOI: 10.1007/s00268-006-0135-0.

20. Cirocchi R, Trastulli S, et al. Total or near-total thyroidectomy versus subtotal thyroidectomy for multinodular non-toxic goitre in adults. Cochrane Database Syst Rev 2015

21. Zeuren R, Biagini $A$, et al. RAl thyroid bed uptake after total thyroidectomy: a novel SPECT-CT anatomic classification system. Laryngoscope 2015 Oct;125(10):2417-2424. DOI: 10.1002/lary.25295.

22. Hisham AN, Aina EN. Zuckerkandl tubercle of the thyroid gland in association with pressure symptoms: a coincidence or consequence? Aust N Z J Surg 2000 Apr;70(4):251.

23. Yun JS, Lee YS, et al. The Zuckerkandl tubercle: a useful anatomical landmark for detecting both the recurrent laryngeal nerve and the superior parathyroid during thyroid surgery. Endocr J 2008 Oct;55(5):925-930.
24. Sackett WR, Reeve TS, et al. Thyrothymic thyroid rests: incidence and relationship to the thyroid gland. J Am Coll Surg 2002 Nov;195(5): 635-640.

25. Dissanayake DDMC, Fernando RF. Lateral approach to the thyroid: a good technique for reoperative thyroid surgery. World J Endocr Surg May-August 2016;8(2):1-2.

26. Levin KE, Clark AH, et al. Reoperative thyroid surgery. Surgery 1992; 111(6):604-609.

27. Rudolph N, Dominguez C, et al. The morbidity of reoperative surgery for recurrent benign nodular goitre: impact of previous unilateral thyroid lobectomy versus subtotal thyroidectomy. J Thyroid Res 2014;2014:1-46.

28. Malik R, Linos D. Intraoperative neuromonitoring in thyroid surgery: a systematic review. World J Surg Aug 2016;40(8):2051-2058. DOI: $10.1007 / \mathrm{s} 00268-016-3594-y$ 